Check for updates

Cite this: RSC Adv., 2019, 9, 2493

Received 7th November 2018 Accepted 14th January 2019

DOI: 10.1039/c8ra09219b

rsc.li/rsc-advances

\section{Chan-Lam coupling reaction of sulfamoyl azides with arylboronic acids for synthesis of unsymmetrical $\mathbf{N}$-arylsulfamides $\dagger$}

\author{
Suk-Young Won, ${ }^{a}$ Seo-Eun Kim, ${ }^{a}$ Yong-Ju Kwon, ${ }^{a}$ Inji Shin, ${ }^{\text {bc }}$ Jungyeob Ham ${ }^{d}$ \\ and Won-Suk Kim (D)*a
}

An efficient method was developed for the synthesis of unsymmetrical $N$-arylsulfamides using sulfamoyl azides and arylboronic acids in the presence of $10 \mathrm{~mol} \%$ of copper chloride as the catalyst. The reaction was facilitated in $\mathrm{MeOH}$ in an open flask at room temperature. Unlike the coupling of sulfamides and boronic acids, the use of sulfamoyl azides was found to be beneficial with respect to the yield and reaction time.

\section{Introduction}

$N$-Arylsulfamides can be found in various therapeutic agents, drugs, and bioactive compounds, such as c-Met inhibitors and $\beta_{3}$-adrenergic agonists (Fig. 1). ${ }^{1}$ Selective inhibition of c-Met signalling is known to have a connection with human cancer was proposed in the case of c-Met kinase inhibitors. ${ }^{1 \boldsymbol{d}}$ In particular, the sulfamide structural motif is the defining characteristic of the distinct inhibitory effect. Moreover, compounds containing unsymmetrical sulfamides are favorable for applications in medicinal chemistry. ${ }^{2}$ Therefore, numerous methods were developed to synthesize these important compounds.

$\mathrm{N}$-Arylsulfamides were conventionally prepared by the reaction involving sulfamoyl chloride derivatives and an amine with a base (Scheme 1, route A). ${ }^{3}$ Despite being an effective approach to produce unsymmetrical $N$-arylsulfamides, it provides low yield as amines exhibit steric hindrance or deficient reactivity. In 2004, a novel intermolecular cross coupling process between $\mathrm{N}, \mathrm{N}$-disubstituted sulfamides and aryl halides using a palladium catalyst was first reported to produce unsymmetrical $\mathrm{N}$ arylsulfamides by L. Alcaraz et al. (Scheme 1, route B). ${ }^{4}$ However, high temperatures to activate the starting reagents, sulfamides, and aryl halides are unavoidable in this approach. A Lossen-like rearrangement was demonstrated and this reaction carried out at room temperature, however, over $12 \mathrm{~h}$ were required to

${ }^{a}$ Department of Chemistry and Nanoscience, Ewha Womans University, Seoul 03760, South Korea.E-mail:wonsukk@ewha.ac.kr

${ }^{b}$ Therapeutics \& Biotechnology Division/Innovative Therapeutics Research Center, Korea Research Institute of Chemical Technology (KRICT), Daejeon 34602, South Korea

'Department of Medicinal and Pharmaceutical Chemistry, University of Science and Technology, Daejeon, 34101, South Korea

${ }^{d}$ Natural Product Research Institute, Korea Institute of Science and Technology (KIST), Gangneung 25451, South Korea

$\dagger$ Electronic supplementary information (ESI) available. See DOI: 10.1039/c8ra09219b synthesize the sulfamides (Scheme 1 , route C). ${ }^{5}$ Therefore, it is still necessary to develop a more efficient and less stringent method to obtain the desired product.

Recently, an improved approach for the synthesis of $\mathrm{N}$-arylsulfonamides and $\mathrm{N}$-arylcarbamates using sulfonyl azides and azidoformates respectively at room temperature in the presence of a copper catalyst and boronic acids has been successfully
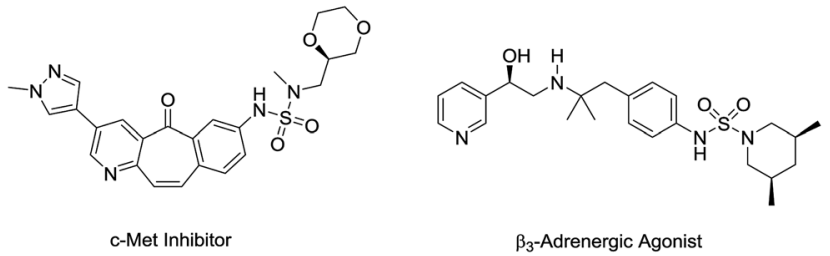

Fig. $1 \mathrm{~N}$-Arylsulfamide-containing bioactive compounds.

(A)

$$
G_{1} L^{-S^{\prime \prime}} \text { IG }_{L G_{2}}^{O}
$$

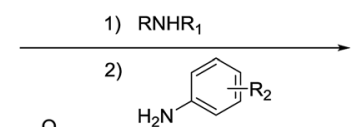

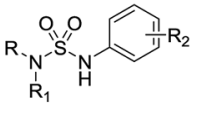

$L G_{1}, L G_{2}=C l$

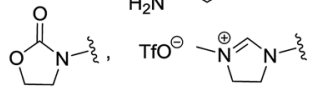

(B)

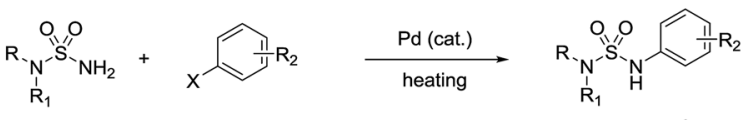

(C)

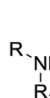
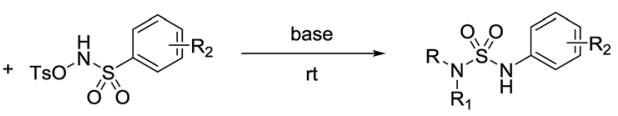

(D)
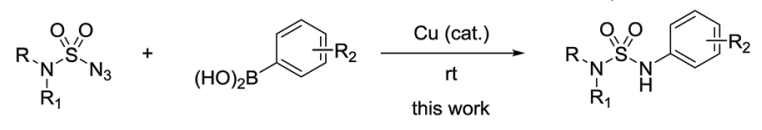

Scheme 1 (A) General routes (B) Pd-catalyzed cross-coupling reaction (C) Lossen-like rearrangement (D) The reaction in the present work, towards the production of unsymmetrical $N$-arylsulfamides. 
Previous work

$$
\text { (A) } \mathrm{R}_{1}
$$

(B) $\mathrm{R}_{1} \mathrm{O}_{\mathrm{N}_{3}}+{ }_{(\mathrm{HO})_{2} \mathrm{~B}}$

Scheme 2 (A) Synthesis of $N$-arylsulfonamides (B) synthesis of $N$ arylcarbamates.

Table 1 Optimization of the $N$-arylation reaction of $N$-benzyl- $N$ methyl-sulfamoyl azide 1 with phenylboronic acid $2^{a}$

\begin{tabular}{|c|c|c|c|c|c|c|}
\hline & & & & $\begin{array}{l}\mathrm{cat}^{\mathrm{a}} \\
\mathrm{mol} \%)\end{array}$ & & \\
\hline & 1 & 2 & & & & $3 a$ \\
\hline Entry & $\mathrm{Cu}$ cat. & Equiv. of 2 & Oxidant & Solvent & Time & Yield of $3 \mathbf{a}^{b}$ \\
\hline 1 & $\mathrm{CuCl}$ & 1.2 & Air & $\mathrm{MeOH}$ & $12 \mathrm{~h}^{c}$ & $72 \%,(83 \%)^{d}$ \\
\hline 2 & $\mathrm{CuCl}$ & 1.5 & Air & $\mathrm{MeOH}$ & $16 \mathrm{~h}^{c}$ & $81 \%,(92 \%)^{d}$ \\
\hline 3 & $\mathrm{CuCl}$ & 2.0 & Air & $\mathrm{MeOH}$ & $45 \mathrm{~min}$ & $91 \%$ \\
\hline $4^{c}$ & $\mathrm{CuCl}$ & 2.0 & Air & $\mathrm{MeOH}$ & $70 \mathrm{~min}$ & $78 \%$ \\
\hline 5 & $\mathrm{CuBr}$ & 2.0 & Air & $\mathrm{MeOH}$ & $2 \mathrm{~h}$ & $87 \%$ \\
\hline 6 & $\mathrm{Cu}(\mathrm{OAc})_{2}$ & 2.0 & Air & $\mathrm{MeOH}$ & $4 \mathrm{~h}$ & $77 \%$ \\
\hline 7 & $\mathrm{CuCl}_{2}$ & 2.0 & Air & $\mathrm{MeOH}$ & $16 \mathrm{~h}$ & $74 \%$ \\
\hline 8 & $\mathrm{CuCl}$ & 2.0 & $\mathrm{Ag}_{2} \mathrm{CO}_{3}$ & $\mathrm{MeOH}$ & $16 \mathrm{~h}^{c}$ & $3 \%,(12 \%)^{d}$ \\
\hline 9 & $\mathrm{CuCl}$ & 2.0 & $\mathrm{O}_{2}$ & $\mathrm{MeOH}$ & $55 \mathrm{~min}$ & $78 \%$ \\
\hline $10^{e}$ & $\mathrm{CuCl}$ & 2.0 & None & $\mathrm{MeOH}$ & $85 \mathrm{~min}$ & $88 \%$ \\
\hline 11 & None & 2.0 & Air & $\mathrm{MeOH}$ & $24 \mathrm{~h}$ & $0 \%$ \\
\hline 12 & $\mathrm{CuCl}$ & 2.0 & Air & $\mathrm{CH}_{2} \mathrm{Cl}_{2}$ & $16 \mathrm{~h}^{c}$ & $0 \%$ \\
\hline 13 & $\mathrm{CuCl}$ & 2.0 & Air & THF & $24 \mathrm{~h}^{c}$ & $17 \%,(45 \%)^{d}$ \\
\hline
\end{tabular}

${ }^{a}$ Reaction conditions: 1.0 equiv. of $\mathbf{1}$, solvent $(0.5 \mathrm{M}), \mathrm{rt}^{b}{ }^{b}$ Isolated yield. ${ }^{c}$ Reaction time based on complete consumption of boronic acid as determined by TLC analysis. ${ }^{d}$ Conversion. ${ }^{e} 5 \mathrm{~mol} \%$ of $\mathrm{CuCl}$.

reported by our group (Scheme 2) ${ }^{6,7}$ We thus envisioned an alternative synthetic method in order to contribute to the existing unsymmetrical $N$-arylsulfamides synthesis. Unlike previous synthetic methods, we expected our process would proceed rapidly at room temperature in high yields without the use of any additives and would not require relatively expensive palladium catalyst (Scheme 1, route D). Furthermore, to the best of our knowledge, the formation of $\mathrm{N}$-arylsulfamides by coppercatalyzed processes has not yet been reported. Therefore, this study aims to present the first copper-catalyzed process for the synthesis of unsymmetrical $N$-arylsulfamides by employing $N, N$ disubstituted sulfamoyl azides and aryl boronic acids at room temperature. However, in general, organic azides are widely used in organic synthesis, but special precautions are necessary when using sulfamoyl azides. ${ }^{8}$

\section{Results and discussion}

An optimization of the Chan-Lam coupling reaction was initially conducted with $N$-benzyl- $N$-methylsulfamoyl azide $\mathbf{1}^{9}$
Table 2 Cu-catalyzed $N$-arylation of $N$-benzyl- $N$-methyl-sulfamoyl azide 1 with boronic acids 3

$$
\text { (1) }
$$

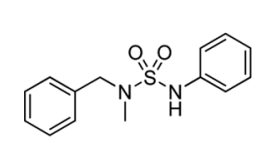

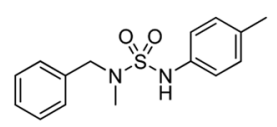

3b, $(82 \%), 45 \mathrm{~min}$

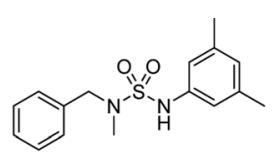

3c, $(90 \%), 45 \mathrm{~min}$<smiles>COc1ccc(NS(=O)(=O)N(C)Cc2ccccc2)cc1</smiles><smiles>COc1cccc(NS(=O)(=O)N(C)Cc2ccccc2)c1</smiles><smiles>COc1ccccc1NS(=O)(=O)N(C)Cc1ccccc1</smiles>

3d, $(90 \%), 45 \mathrm{~min} \quad 3 e,(99 \%), 45 \mathrm{~min}$ 3f, $(30 \%),(46 \%)^{b}, 3 h^{c}$<smiles>CN(Cc1ccccc1)S(=O)(=O)Nc1ccc2ccccc2c1</smiles>

3g, $(89 \%), 40 \mathrm{~min}$<smiles>CN(Cc1ccccc1)S(=O)(=O)Nc1ccc2c(c1)OCO2</smiles>

3h, $(80 \%), 55 \mathrm{~min}$<smiles>C=Cc1ccc(NS(=O)(=O)N(C)Cc2ccccc2)cc1</smiles>

$3 i,(88 \%), 70 \mathrm{~min}$<smiles>CN(Cc1ccccc1)S(=O)(=O)Nc1ccc(F)cc1</smiles>

3 I, $(91 \%), 3 \mathrm{~h}$<smiles>CN(Cc1ccccc1)S(=O)(=O)Nc1ccc(Br)cc1</smiles>

3 j, $(80 \%), 12 \mathrm{~h}$

3k, $(71 \%), 12 \mathrm{~h}$<smiles>CCCOC(=O)c1ccc(NS(=O)(=O)N(C)Cc2ccccc2)cc1</smiles>

$3 \mathrm{~m},(80 \%), 3 \mathrm{~h}$

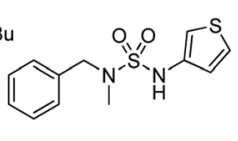

3n, $(82 \%),(92 \%)^{b}, 12 h^{c}$
${ }^{a}$ Reaction conditions: 1.0 equiv. of $1,2.0$ equiv. of $3,10 \mathrm{~mol} \%$ of $\mathrm{CuCl}$, $\mathrm{MeOH}(0.5 \mathrm{M})$, air, rt. ${ }^{b}$ Conversion. ${ }^{c}$ Reaction time based on complete consumption of boronic acid as determined by TLC analysis.

with phenylboronic acid 2 (Table 1). The reaction was first investigated with a $\mathrm{CuCl}$ catalyst and 1.2 equiv. of phenylboronic acid 2 in the solvent $\mathrm{MeOH}$ in an open flask. The desired product 3a was generated in $72 \%$ yield with $83 \%$ conversion in $12 \mathrm{~h}$ (Table 1, entry 1). However, when 1.5 equiv. of boronic acid was used, the product was obtained with a slightly higher yield of $81 \%$ with $92 \%$ conversion in $16 \mathrm{~h}$ (Table 1, entry 2).

Finally, the use of 2.0 equiv. of phenylboronic acid 2 produced the highest yield of $91 \%$ of $N$-arylsulfamide $3 a$ (Table 1 , entry 3 ). When the catalyst loading was reduced from $10 \mathrm{~mol} \%$ to $5 \mathrm{~mol} \%$, 3a was isolated at a lower yield (Table 1, entry 4). Moreover, the use of other copper catalysts or addition of $\mathrm{Ag}_{2} \mathrm{CO}_{3}$ and pure oxygen instead of air produced a lower yield (Table 1, entries 5-9). The use of argon was also furnished the desired product in a slightly lower $88 \%$ yield in $85 \mathrm{~min}$ (Table 1 , entry 10). The absence of the catalyst resulted in $0 \%$ yield without conversion, thus demonstrating the importance of the $\mathrm{Cu}$ catalyst in this method (Table 1, entry 11). Furthermore, when different solvents having less polarity were used, the yield of 3a was poor (Table 1, entries 12 and 13). 
Table 3 Cu-catalyzed $N$-arylation of phenylboronic acid 2 with various sulfamoyl or aryloxysulfonyl azides 4
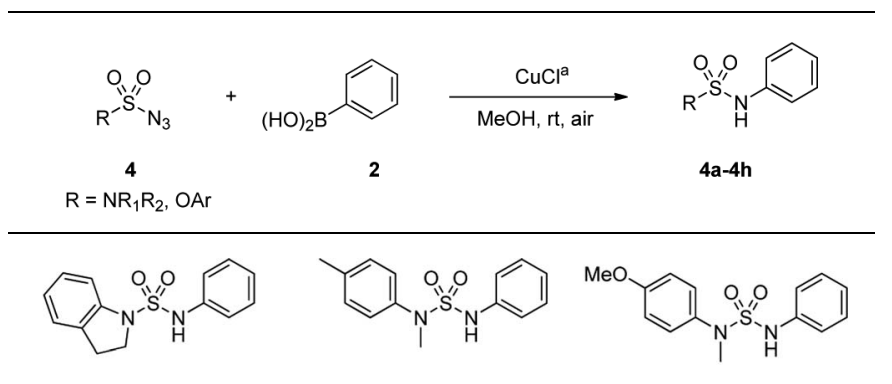

4a, (85\%), $50 \mathrm{~min}$

4b. $(87 \%), 85 \mathrm{~min}$

4c, $(94 \%), 1 \mathrm{~h}$<smiles>COc1ccc(CCN(C)S(=O)(=O)Nc2ccccc2)cc1OC</smiles>

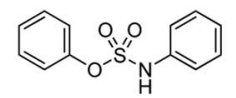

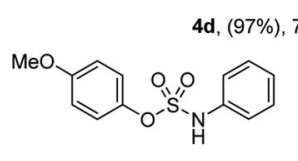

4f, (76\%), $35 \mathrm{~min}$

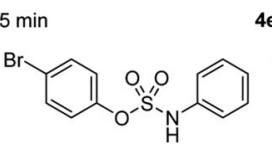

4g. (68\%), 40 min 4e, $(67 \%), 30 \mathrm{~min}$

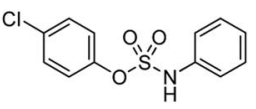

4h, $(66 \%), 40 \mathrm{~min}$
${ }^{a}$ Reaction conditions: 1.0 equiv. of $4,2.0$ equiv. of $2,10 \mathrm{~mol} \%$ of $\mathrm{CuCl}$, $\mathrm{MeOH}$ (0.5 M), air, rt.

The scope of the copper-catalyzed coupling reactions using $N$-benzyl- $N$-methyl-sulfamoyl azide $\mathbf{1}$ and various boronic acids 3 was investigated under this optimized condition. As illustrated in Table 2, most of the boronic acids that were applied in the optimal conditions produced the desired products with good to excellent yields. However, in the case of 3f, yield of only $30 \%$ with $46 \%$ conversion in $3 \mathrm{~h}$ was achieved due to steric hindrance. In particular, halo-substituted aryl boronic acids exhibited less reactivity and produced $3 \mathbf{j}$ and $\mathbf{3 k}$ with yields of $80 \%$ and $71 \%$, respectively, after $12 \mathrm{~h}$. In addition, the use of 3thienylboronic acid yielded $82 \%$ of the desired $3 \mathbf{n}$ with $92 \%$ conversion after prolonged reaction time of $12 \mathrm{~h}$. The competing homocoupling of arylboronic acids in the presence of $\mathrm{CuCl}$ and $\mathrm{MeOH}$ completely consumed the boronic acids when 2-methoxyphenyl boronic acid or 3-thienylboronic acid was used. ${ }^{10}$

Moreover, the reactions of various sulfamoyl azides 4 with phenylboronic acid 2 were investigated. As shown in Table 3, the desired 4a-d were obtained at a good to excellent yield within $90 \mathrm{~min}$. In addition, by using aryloxysulfonyl azides, ${ }^{11}$ the formation of $\mathrm{N}$-arylsulfamic esters (Table 3, 4e-h) ${ }^{\mathbf{1 1 c}}$ was expected, and their moderate to good yield suggests that the result depends on the reactivity of the azides. The yield gradually improved when an electron-donating group was substituted for the aryloxysulfonyl azides.

Next, the application of various phenylboronic acid derivatives as coupling partners in the optimized condition was investigated (Scheme 3). The use of phenyltrifluoroborate 5 yielded $42 \%$ of $3 \mathrm{a}$ with $86 \%$ conversion, and with pinacol phenylboronate $\mathbf{6}, 31 \%$ of 3 a was obtained with $60 \%$ conversion

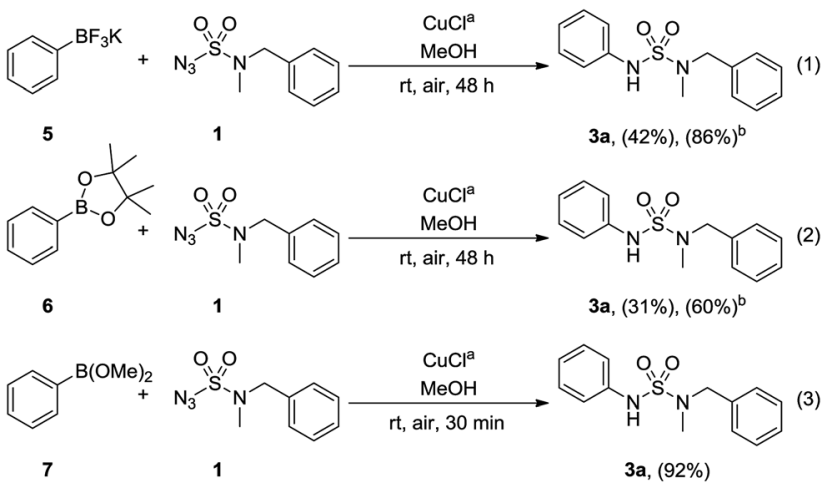

Scheme 3 Cu-catalyzed $N$-arylation of $N$-benzyl- $N$-methyl-sulfamoyl azide 1 with boronic acid derivatives. ${ }^{\mathrm{a}}$ Reaction conditions: 1.0 equiv. of 1, 2.0 equiv. of boronic acid derivative, $10 \mathrm{~mol} \%$ of $\mathrm{CuCl}$, $\mathrm{MeOH}(0.5 \mathrm{M})$, air, rt. ${ }^{b}$ Conversion.

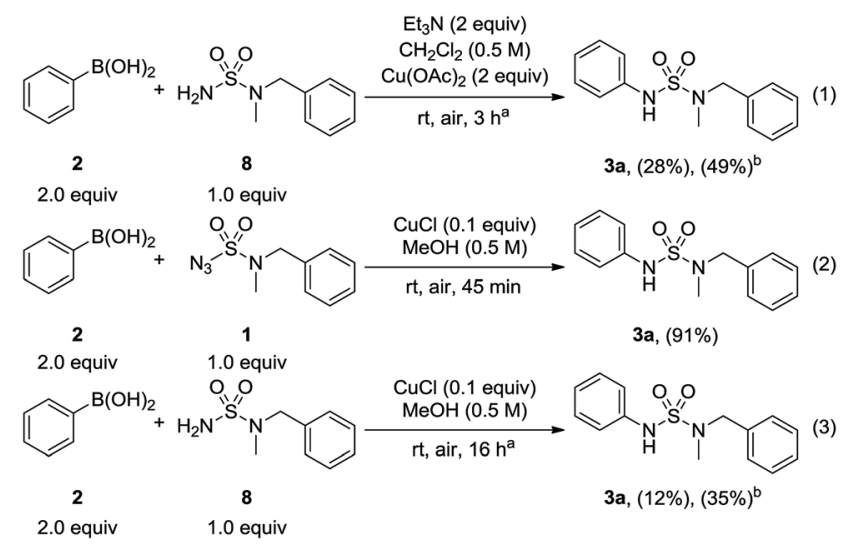

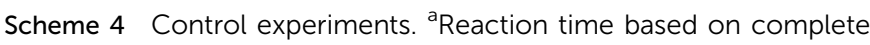
consumption of boronic acid as determined by TLC analysis. ${ }^{\mathrm{b} C o n v e r s i o n .}$

(Scheme 3, eqn (1) and (2)). Lastly, when dimethyl phenylboronate 7 was used, the desired sulfamide 3a was synthesized at $92 \%$ yield in $30 \mathrm{~min}$ (Scheme 3 , eqn (3)).

A control experiment was then carried out by using $N$-benzyl$N$-methylsulfamide 8 and phenylboronic acid 2 under conventional Chan-Lam coupling conditions ${ }^{\mathbf{1 2}}$ (Scheme 4, eqn (1)). Despite the extended reaction time, the desired $N$-arylsulfamide 3a was obtained at a yield of only $28 \%$ with $49 \%$ conversion. Next, sulfamide $\mathbf{8}$ was used in the optimized condition to investigate the influence of sulfamoyl azide 1 (Scheme 4, eqn (3)). Only a yield of $12 \%$ was obtained with a conversion of $35 \%$ over $16 \mathrm{~h}$ compared to the yield of $91 \%$ produced by sulfamoyl azide over 45 min (Scheme 4, eqn (2)). In view of these results, it could be hypothesized that sulfamoyl azide has a major impact on the synthesis of $\mathrm{N}$-arylsulfamides in this method.

The possible mechanism for the Chan-Lam coupling between sulfamoyl azides and arylboronic acids is presented below (Scheme 5). ${ }^{7,13}$ At first, the sulfamoyl azides coordinate with the $\mathrm{Cu}(\mathrm{I})$ salt $\mathbf{A}$ that provides copper nitrene and are transformed to $\mathrm{Cu}(\mathrm{II})$ complex $\mathbf{B} .^{\mathbf{1 4}}$ Subsequently, the aryl boronic acid is in equilibrium with the methyl boronate ester, ${ }^{15}$ 


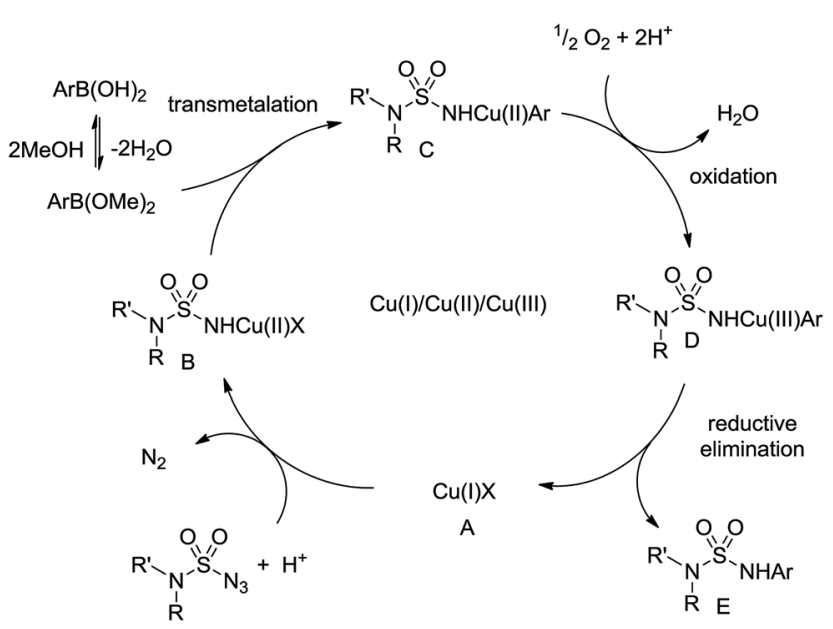

Scheme 5 Possible mechanism.

which undergoes transmetalation with $\mathbf{B}$ to produce $\mathrm{Cu}$ (II) complex $\mathbf{C}$. After air oxidation of $\mathbf{C}$, the $\mathbf{C u}(\mathrm{III})$ complex $\mathbf{D}$ is obtained and $\mathbf{E}$ is derived with the regeneration of the $\mathrm{Cu}(\mathrm{I})$ catalyst $\mathbf{A}$ through reductive elimination.

\section{Conclusions}

In summary, this study explained the Chan-Lam coupling reaction between sulfamoyl azides and arylboronic acids for synthesizing unsymmetrical $N$-arylsulfamides. The reaction was carried out in the presence of $10 \mathrm{~mol} \%$ of the copper chloride catalyst at room temperature in an open flask without any additional additives. The scope of this method employing various sulfamoyl azides and boronic acids was demonstrated. The sulfamoyl azides were established as efficient precursor of the reaction with considerable effect on the yield and reaction time. The application of other organic azides for this method is under investigation.

\section{Experimental}

\section{General procedure for synthesis of unsymmetrical $\mathrm{N}$ - arylsulfamides}

A sealed tube was charged with an arylboronic acid $(2.0 \mathrm{mmol})$, $\mathrm{CuCl}(10 \mathrm{~mol} \%)$ and the corresponding sulfamoyl azide (1.0 $\mathrm{mmol}) . \mathrm{MeOH}(1.0 \mathrm{~mL})$ was then added to the flask. The reaction mixture was stirred at room temperature in an open flask. After completion of the reaction, the reaction mixture was filtered through celite and washed with EtOAc. The filtrate was collected and concentrated under reduced pressure. The crude product was purified by flash column chromatography on silica gel to obtain the desired product.

\section{Conflicts of interest}

There are no conflicts to declare.

\section{Acknowledgements}

This work was supported by a grant from the Basic Science Research Program through the National Research Foundation of Korea (NRF) (2018R1A2B6005533), the Korea Institute of Science and Technology (KIST) (No. 2Z05310) and the New \& Renewable Energy of the Korea Institute of Energy Technology Evaluation and Planning (KETEP) grant (No. 20163030013900).

\section{Notes and references}

1 (a) R. Kuang, J. B. Epp, S. Ruan, L. S. Chong, R. Venkataraman, J. Tu, S. He, T. M. Truong and W. C. Groutas, Bioorg. Med. Chem., 2000, 8, 1005; (b) S. He, R. Kuang, R. Venkataraman, J. Tu, T. M. Truong, H.-K. Chan and W. C. Groutas, Bioorg. Med. Chem., 2000, 8, 1713; (c) J. Zhong and X. Gan, Bioorg. Med. Chem., 2004, 12, 589; (d) J. D. Katz, J. P. Jewell, D. J. Guerin, J. Lim, C. J. Dinsmore, S. V. Deshmukh, B.-S. Pan, C. G. Marshall, W. Lu, M. D. Altman, W. K. Dahlberg, L. Davis, D. Falcone, A. E. Gabarda, G. Hang, H. Hatch, R. Holmes, K. Kunii, K. J. Lumb, B. Lutterbach, R. Mathvink, N. Nazef, S. B. Patel, X. Qu, J. F. Reilly, K. W. Rickert, C. Rosenstein, S. M. Soisson, K. B. Spencer, A. A. Szewczak, D. Walker, W. Wang, J. Young and Q. Zeng, J. Med. Chem., 2011, 54, 4092.

2 (a) C. H. Lee and H. J. Kohn, J. Pharm. Sci., 1990, 79, 716; (b) A. Martinez, C. Gil, C. Perez, A. Castro, C. Prieto, J. Otero, G. Andrei, R. Snoeck, J. Balazarini and E. D. Clercq, J. Med. Chem., 2000, 43, 3267.

3 For selected examples: (a) J.-L. Montero, G. Dewynter, B. Agoh, B. Delaunay and J.-L. Imbach, Tetrahedron Lett., 1983, 24, 3091; (b) S. Beaudoin, K. E. Kinsey and J. F. Burns, J. Org. Chem., 2003, 68, 115; (c) A. Borghese, L. Antoine, J. P. VanHoeck, A. Mockel and A. Merschaert, Org. Process Res. Dev., 2006, 10, 770; (d) C. Guo, L. Dong, S. Kephart and X. Hou, Tetrahedron Lett., 2010, 51, 2909.

4 L. Alcaraz, C. Bennion, J. Morris, P. Meghani and S. M. Thom, Org. Lett., 2004, 6, 2705.

5 L. Pantaine, F. Richard, J. Marrot, X. Moreau, V. Coeffard and C. Greck, Adv. Synth. Catal., 2016, 358, 2012.

6 S.-Y. Moon, J. Nam, K. Rathwell and W.-S. Kim, Org. Lett., 2014, 16, 338.

7 S.-Y. Moon, U. B. Kim, D.-B. Sung and W.-S. Kim, J. Org. Chem., 2015, 80, 1856.

8 S. Bräse, C. Gil, K. Knepper and V. Zimmerman, Angew. Chem., Int. Ed., 2005, 44, 5188.

9 J. C. Culhane and V. V. Fokin, Org. Lett., 2011, 13, 4578.

10 Homocoupling of arylboronic acid in the presence of $\mathrm{CuCl}$ in $\mathrm{MeOH}$ has been reported by Luo and Cheng. See: G. Cheng and M. Luo, Eur. J. Org. Chem., 2011, 2519.

11 (a) T. Yang, H. Cui, C. Zhang, Li. Zhang and C.-Y. Su, ChemCatChem, 2013, 5, 3131; (b) V. Subbarayan, L.-M. Jin, C. Xin and X. P. Zhang, Tetrahedron Lett., 2015, 56, 3431; (c) B. Yang, Z. Sun, C. Liu, Y. Cui, Z. Guo, Y. Ren, Z. Lu and S. Knapp, Tetrahedron Lett., 2014, 55, 6658. 
12 D. M. T. Chan, K. L. Monaco, R.-P. Wang and M. P. Winters, Tetrahedron Lett., 1998, 39, 2933.

13 (a) P. Y. S. Lam, C. G. Clark, S. Saubern, J. Adams, K. M. Averill, D. M. T. Chan and A. Combs, Synlett, 2000, 674; (b) A. E. King, T. C. Brunold and S. S. Stahl, J. Am. Chem. Soc., 2009, 131, 5044; (c) A. E. King, T. C. Brunold,
L. M. Huffman, A. Casitas, M. Costas, X. Ribas and S. S. Stahl, J. Am. Chem. Soc., 2010, 132, 12068.

14 (a) E. Haldón, E. Álvarez, M. C. Nicasio and P. J. Pérez, Chem. Commun., 2014, 50, 8978; (b) E. Haldón, M. Besora, I. Cano, X. C. Cambeiro, M. A. Pericás, F. Maseras, M. C. Nicasio and P. J. Pérez, Chem.-Eur. J., 2014, 20, 3463.

15 D. G. Hall, Boronic Acids, Wiley-VCH, Weinheim, 2005. 